\title{
BIOCHEMICAL SCREENING OF MARINE MICROMONOSPORA MARINA KPMS1 (MH036351) AND ITS ANTIBACTERIAL ACTIVITY AGAINST MULTIDRUG RESISTANT BACTERIA
}

\author{
MOHAMED MAHROOP RAJA M*, RAJA A, REEHANA N \\ Department of Microbiology, Jamal Mohamed College (Autonomous), Tiruchirappalli - 620 020, Tamil Nadu, India. \\ Email: mahroop_raja07@yahoo.co.in
}

Received: 20 September 2018, Revised and Accepted: 09 November 2018

\begin{abstract}
Objective: The present investigation aimed at the screening of pharmaceutically potential antimicrobial metabolite isolated from marine Micromonospora sp. to combat the multidrug-resistant bacteria.

Materials and Methods: The Marine sediments were randomly collected for the isolation of Micromonospora sp., from Gulf of Mannar, East Coastal Region, located at Kayalpatnam, Tuticorin district, Tamil Nadu, India. The Micromonospora sp. was cultivated by serial dilution and crowed plating method on actinomycetes isolation agar. The isolated colonies were identified by morphological, cultural, and biochemical methods. The antibacterial study of Micromonospora sp. was performed on Mueller-Hinton agar medium against multidrug-resistant bacteria isolated from urinary tract infection. The antibacterial compound was separated and characterized by Fourier-transform infrared (FT-IR) and nuclear magnetic resonance (NMR) spectrum.

Results: Based on the morphological, cultural, and biochemical studies, the isolated colonies were found to be the genera of Micromonospora. Among Micromonospora genera, Micromonospora marina KPMS1 strain showed potent antibacterial activity against multidrug-resistant Escherichia coli, Pseudomonas aeruginosa, and Enterococcus faecalis. The FT-IR and NMR studies showed the structural elucidation of active compounds derived from M. marina KPMS1. The 16S rRNA sequences of M. marina KPMS1 (MH036351) strain were blasted and deposited in the GenBank of National Center for Biotechnology Information.
\end{abstract}

Conclusion: The results of the study were concluded that microbial compounds are the promising sources of nearly all of the antibiotics produced by marine Micromonospora sp. The detection of new biological compounds was considered to represent a novel species of the genus Micromonospora which have been used for clinical treatment against multidrug-resistant bacteria and were pharmaceutically important.

Keywords: Biochemical studies, 16S rRNA sequences, Antimicrobial, Antibiotics, Multidrug-resistant bacteria.

(C) 2019 The Authors. Published by Innovare Academic Sciences Pvt Ltd. This is an open access article under the CC BY license (http://creativecommons. org/licenses/by/4. 0/) DOI: http://dx.doi.org/10.22159/ajpcr. 2019.v12i2.29872

\section{INTRODUCTION}

The Actinobacteria are one of the plentiful sources of novel biological metabolites. Among Actinobacteria, the genera of Micromonospora have been accommodated as a reservoir of antimicrobial agent and novel secondary metabolite producer next to the Streptomyces genera [1]. The genus Micromonospora has been documented as aerobic, spore-forming Gram-positive, filamentous bacteria which are characterized by aerial and substrate mycelia. Micromonospora sp. produced single non-motile spores on substrate mycelia. Many species of the genus Micromonospora have been isolated from diverse environments. More than $50 \%$ of bioactive compounds were derived from different regions in soil produced by soil-inhabiting genera Micromonospora [2]. The few are found in root nodules and sea sand [3]. Currently, Micromonospora sp. was isolated from marine sponge, marine water, and it sediments [4]. Not only soil region, the marine water and its sediments also harbor microbial rich environment which have abundant microbial communities ranging from $10^{6}$ to $10^{9} \mathrm{CFU} / \mathrm{g}$ [5]. The potential source of bioactive metabolites was produced by Micromonospora strains which are pharmaceutically important. Among these compounds, aminoglycoside group of antibiotics is predominant followed by macrolide antibiotics [6]. Among 23,000 bioactive compounds, more than 740 bioactive metabolites isolated from family Micromonosporaceae such as gentamicin, neomycin, sagamicin, mutamicin, verdamicin, rifamycins, sisomicin, erythromycin B, and fortimicins have been used for clinical treatment [7]. The marine Micromonospora not only have several new species but also have number of novel secondary metabolites that have different mechanisms of action in worldwide [8]. The present study was aimed to identify the antimicrobial compound isolated from marine Micromonospora sp. and its antibacterial activity against the multidrug-resistant bacteria.

\section{MATERIALS AND METHODS}

Materials

All chemicals were purchased from Merck (Germany), HiMedia (India), or Thermo Fisher Scientific Pvt., Ltd. (India) unless otherwise indicated. All buffers and reagents used in this study were prepared in distilled water.

\section{Sample collection and cultivation}

The marine sediment samples were collected and air dried at room temperature. $1 \mathrm{~g}$ marine sediment was suspended in $9 \mathrm{ml}$ of distilled water and serially diluted upto $10^{-9}$ dilution. $1 \mathrm{ml}$ of each dilution series was inoculated into Actinomycete Isolation Agar (AIA) supplemented with cycloheximide $(50 \mu \mathrm{g} / \mathrm{ml})$ and incubated at $28^{\circ} \mathrm{C}$ for $2-3$ weeks. The selected colonies were subcultured and maintained on AIA with $25 \% \mathrm{v} / \mathrm{v}$ glycerol at $4^{\circ} \mathrm{C}[9]$.

\section{Morphological identification}

Gram reaction

Most of the actinobacteria can be differentiated by their gram reaction due to differences in their cell wall structure. In this technique, the cell smear was mad and flooded with complex chemical stains and focused on the microscope under $\times 100$ magnification.

\section{Slide culture analysis}

The morphology of spore based on the aerial and substrate mycelium was observed by slide culture method. The agar blocks were prepared using AIA. The selected colonies were inoculated in every corner of the agar blocks. The setup was kept in moist chamber under incubation at 
$28^{\circ} \mathrm{C}$ for 1 week. After incubation, the aerial and substrate mycelia were examined under high power magnification using Sudan black stain. The spore morphology was examined under bright-field microscope using $0.1 \%$ crystal violet stain along with a drop of culture.

\section{Biochemical reaction}

The biochemical and physiological properties were identified by indole production test, methyl red test, Voges-Proskauer test, citrate utilization test, catalase test, oxidase test, starch hydrolysis test, urea hydrolysis test, and utilization of triple sugar iron agar test [10].

\section{L-asparaginase production}

L-asparaginase production was carried out by submerged fermentation on minimal media broth incorporated with phenol red indicator [11]. The selected colonies were inoculated and incubated in a rotary shaker at $28^{\circ} \mathrm{C}$ for $24 \mathrm{~h}$. At the end of the incubation, the crude enzyme was prepared by centrifugation at $10,000 \mathrm{rpm}$ for $20 \mathrm{~min}$. The cell-free supernatant was separated by centrifuging at 10,000 rpm for $20 \mathrm{~min}$.

\section{Antibacterial studies}

For fermentation studies, the selected strains were inoculated on ISP 4 medium and incubated under $150 \mathrm{rpm}$ in a rotary shaker at $28^{\circ} \mathrm{C}$ for 2 weeks. After incubation, the growth was analyzed by optimal density at $600 \mathrm{~nm}$, and the dry weight of the mycelium was measured and correlated with the growth of the isolate. The cell-free supernatant was collected by centrifugation at 10,000 rpm from fermented broth and filtrated by nitrocellulose filter paper. The cell-free culture filtrate was mixed with an equal amount of ethyl acetate and kept under $200 \mathrm{rpm}$ overnight. The solvent phase was collected and tested against multidrug-resistant bacteria.

Preliminary antibacterial activity was performed on Mueller-Hinton agar by agar well diffusion method. The $100 \mu \mathrm{l}$ of crude ethyl acetate extract of selected active strain was tested against multidrug-resistant bacteria and incubated at $37^{\circ} \mathrm{C}$ for $24 \mathrm{~h}$. After incubation, all plates were examined for the zone of inhibition around the wells.

\section{Biological activity}

The purification of antimicrobial compounds was performed by thin-layer chromatography (TLC) plate [12]. The crude extract of selected strain was applied on marked spot using a capillary tube and the spots were dried. The solvent of n-butanol: ethyl acetate: water (9:9:1) was prepared, and the TLC plate was vertically placed into solvent chamber. The distance of solvent moved up to $2 \mathrm{~cm}$ below the top of TLC plate and the plate was removed from solvent chamber. The fractions were detected under ultraviolet chamber, and the $R f$ values were recorded:

$$
R_{f}=\text { Distance of solute/distance of solvent }
$$

TLC fractions were separated and $100 \mu \mathrm{l}$ of $5 \mathrm{mg} / \mathrm{ml}$ concentration of selected fraction was loaded on sterile disc. The multidrug-resistant bacteria Escherichia coli, Pseudomonas aeruginosa, and Enterococcus faecalis were inoculated over the Mueller-Hinton agar plates. Standard drug cefotaxime $(10 \mathrm{mg})$ was placed on the agar plates and incubated at $37^{\circ} \mathrm{C}$ for $24 \mathrm{~h}$. After incubation, the zone of inhibition was measured.

The minimal inhibitory concentration (MIC) was performed on Mueller-Hinton broth by tube dilution method. In each of the test tubes, $2 \mathrm{ml}$ of Mueller-Hinton broth was added. Various concentrations of standard antibiotic and active compound were prepared by dilution of $\times 2$ concentration of drug. The concentration of diluted antibiotics and sample was $100,50,25,12.5,6.25,3.12,1.56$, and $0.78 \mu \mathrm{g} / \mathrm{ml}$. A tube without drug was negative control and uninoculated tube served as sterility control. After dilution, test organism was inoculated into all tubes and incubated for $24 \mathrm{~h}$. After incubation, the lowest concentration of antibiotics and its growth inhibition was recorded by the addition of resazurin indicator [13].
Characterization of active compound Fourier-transform infrared (FT-IR) and nuclear magnetic resonance (NMR) spectrum The active compound of Micromonospora was subjected to FT-IR spectral analysis. The FT-IR spectrum ranges between 4000 and $400 \mathrm{~cm}^{-1}$ with the resolution of $0.9 \mathrm{~cm}^{-1}$. The FT-IR spectrum was recorded with $95 \%$ methanol. The resulting FT-IR spectral pattern was analyzed and confirmed the presence of functional groups in the absorption peaks which were compared with known signatures of identified standard.

The NMR ( $\mathrm{C}^{13}$ and $\mathrm{H}^{1} \mathrm{NMR}$ ) spectroscopy was used to determine the chemical structural properties of active compound derived from Micromonospora strain. The NMR experiment was conducted on a $400 \mathrm{MHz}$ JOEL NMR spectrophotometer at the National Institute of Technology, Tiruchirappalli, Tamil Nadu, India.

\section{Molecular characterization and phylogenetic tree analysis}

The chromosomal DNA isolation was performed by the exponential growth of Micromonospora on actinomyceye isolation broth. The cell pellet was collected and resuspended in $567 \mu \mathrm{l}$ of TE buffer, $30 \mu \mathrm{l}$ of $10 \%$ SDS, $3 \mu \mathrm{l}$ of $20 \mathrm{mg} / \mathrm{ml}$ proteinase $\mathrm{K}$, and incubated at $37^{\circ} \mathrm{C}$. Addition of $100 \mu \mathrm{l}$ of $5 \mathrm{M} \mathrm{NaCl}$ and $80 \mu \mathrm{l}$ of CTAB-NaCl solution was mixed well on a vortex mixer until the cell suspension became translucent and incubated at $65^{\circ} \mathrm{C}$ for $10 \mathrm{~min}$. An equal volume of chloroform and isoamyl alcohol was added and centrifuged at $5000 \mathrm{rpm}$ for $5 \mathrm{~min}$. The aqueous phase was aspirated and mixed with an equal volume of phenol, chloroform, and isoamyl alcohol which were centrifuged for $5 \mathrm{~min}$. The aqueous phase was collected and transferred to $1.5 \mathrm{ml}$ microfuge tube. Subsequently, 0.6 volume of isopropanol and $100 \mu \mathrm{l}$ of $3 \mathrm{M}$ sodium acetate were added. The precipitate was collected by centrifugation and washed with $70 \%$ ethanol, dried, and dissolved in $100 \mu \mathrm{l}$ of TE buffer.

Polymerase chain reaction (PCR) amplification of 16SrRNA gene sequence was carried out by two primers for matching most of known eubacteria order. The amplification of $16 \mathrm{~S}$ rRNA gene sequence was carried out using the forward primer F243 (5'-GGATGAGCCCGCGGCCTA-3') and reverse primer R513GC (5'-CGGCCGCGGCTGCTGGCACGTA-3') with an activation temperature of $95^{\circ} \mathrm{C}$ for $5 \mathrm{~min}$, followed by denaturation of $94^{\circ} \mathrm{C}$ for 1 min, the primer annealing at $52^{\circ} \mathrm{C}$ for $0.5 \mathrm{~min}$, elongation at $72^{\circ} \mathrm{C}$ for 2 $\mathrm{min}$ and the final elongation temperature at $72^{\circ} \mathrm{C}$ for $10 \mathrm{~min}$. The $5 \mu \mathrm{l}$ of the PCR product was loaded on $1.2 \%$ agarose gel in $\times 1$ Tris-borate-EDTA buffer and stained with ethidium bromide $0.5 \mu \mathrm{l} / \mathrm{ml}$. The PCR product was precipitated by polyethylene Glycol (PEG)-NaCl $(20 \%$ PEG in $2.5 \mathrm{M} \mathrm{NaCl}$ ) precipitation at $37^{\circ} \mathrm{C}$ for $30 \mathrm{~min}$. The reaction mixture was centrifuged at $12,000 \mathrm{rpm}$ for $30 \mathrm{~min}$ at room temperature. The supernatant was discarded and the pellet was washed twice with 70\% ethanol. The forward and reverse DNA sequencing reaction of PCR amplicon was carried out using BDT v 3.1 cycle sequencing kit on ABI $3730 \times$ l genetic analyzer.

The reference sequence required for comparison was downloaded from the GenBank using BLASTN sequence based retrieval system from GenBank (URL http://www.ncbi.nlm.nih.g) using our sequence as the query. Based on the sequenced data, the phylogenetic tree was constructed using the bioinformatics tool MEGA 5.05 for aligning the sequences by neighbor-joining method. The 16SrRNA sequences for the Micromonospora have been deposited in GenBank using sequin (http:// www.ncbi.nlm.nib.gov/genebank)

\section{RESULTS AND DISCUSSION}

\section{Collection site and morphological studies}

The collection site of marine sediments was located at Gulf of Mannar, East Coastal Region, Kayalpatnam, Tuticorin district, Tamil Nadu, India. East Coastal Region is bestowed with rich natural flora which has been considered as a potential source of marine Micromonospora was studied for its bioactivity. The physiological and climatic condition of marine sediment region of this site has resulted in diverse type bio-organism 
contributing to enrich the biological diversity. The collection marine sediments were done randomly. The sediments were taken $0-5 \mathrm{~cm}$ depth. The isolation of Micromonospora was performed using serial dilution and plating method by AIA supplemented with cycloheximide. The specific antibiotics were added into the isolation media which is used to suppress the growth of other actinobacteria [14]. The growths of marine Micromonospora colonies were recognized by their mycelium formation. All the Micromonospora colonies were subcultured on AIA slants. The marine sediments were screened and the Micromonospora colonies were isolated, and the numbers of colonies were calculated as $6 \times 10^{6} \mathrm{CFU} / \mathrm{g}$. All the isolates were identified at their generic level based on the colony morphology and microscopic morphology. The ecological niche of marine sediments may have the valuable source for the isolation of novel Micromonospora with the potential to produce new secondary metabolites [15]

The identification of strains was observed by both morphological and cultural characteristics, revealing that most of the isolates were showed the nature of color such as greenish gray, dull white, whitish ash, dark gray, brownish yellow, and whitish gray on AIA. The colonies were elevated 3-4 mm in diameter, initially had a smooth appearance, and later developed the rough colonies. The aerial mycelium absent in all isolates except KPMS10 developed a weft of aerial mycelium which is granular or powdery in nature. All isolates produced single and non-motile spore on substrate mycelium. The pigments were raised in four isolates except KPMS17and KPMS19. Two isolates KPMS1 and KPMS10 were produced melanoid pigments [Table 1]. All the Micromonospora sp. showed septate hyphae with monospore on substrate mycelium by slide culture methods. The present study revealed that all Micromonospora isolates were found to be Gram-positive cell wall. The Micromonospora are currently updated with spore-forming Gram-positive nature of bacteria that form extensive branching of substrate mycelia [16].

\section{Carbohydrate utilization}

The Four isolates were found to be positive for triple sugar iron test with acid butt and alkaline slant. Only two strains of KPMS 9 and KPMS 19 produced acid butt and acid slant with gas production. The potent strain was tentatively identified by the utilization of different carbohydrate source that they belong to distinct taxonomic groups which have been well documented [17].

\section{Biochemical screening}

The biochemical characteristics of Micromonospora strains showed positive results on indole and urease. Four isolates showed methyl red except KPMS10 and KPMS17. Two isolates KPMS10 and KPMS17 were positive in Voges-Proskauer. All the strains were negative on citrate utilization test. Among six strains, three were catalase and oxidase positive and two were starch positive [Table 2]. The Micromonospora genera were further identified using physiological and biochemical tests. This finding gives an initial recognition as novel taxa isolated from marine sediments [18]. The ability of starch, casein, and urease hydrolysis is immense importance for both practical and taxonomical approaches considered for the proper identification of Micromonospora genera which has been documented [19].

Among six isolates, KPMS1 and KPMS10 showed L-asparaginase activity on minimal broth medium incorporated with phenol red indicator, glucose, and yeast extract as carbon and nitrogen substrates. After incubation, the medium turned pink color due to the production of ammonia which indicated the positive result of L-asparaginase production. The marine actinobacteria are serving as a good source of L-asparaginase enzyme and used as a chemotherapeutic agent [20].

\section{Antibacterial studies}

The antibacterial screening was carried out for Micromonospora strains on ISP 4 medium using ethyl acetate extract at a concentration of $2: 1(\mathrm{v} / \mathrm{v})$. The quantity of concentrated product was calculated by the initial weight of watch glass (g) subtracted by final weight of watch glass (g) equal to concentrated component weight (g). The concentrated components were redissolved in distilled water and analyzed for secondary screening process. In screening process, all Micromonospora strains were tested against multidrug-resistant bacteria $E$. coli, P. aeruginosa, and E. faecalis isolated from urinary tract infection (UTI) infection.

In preliminary screening, Micromonospora marina KPMS1 was highly sensitive to multidrug-resistant bacteria isolated from UTI. The highest inhibition showed in Klebsiella pneumoniae $(18 \pm 0.04 \mathrm{~mm})$ with a relative zone of inhibition of $88 \%, P$. aeruginosa $(17 \pm 0.01 \mathrm{~mm})$ with relative zone of inhibition of $76 \%$, and Enterococcus faecium (16 $\pm 0.08 \mathrm{~mm}$ ) with relative zone of inhibition of $80 \%$. The comparison was done by standard antibiotic cefotaxime, and the percentage of relative inhibitory zone was found to be ranged between $76 \%$ and $88 \%$ [Table 3].

The bioactive compound extracted from $M$. marina KPMS1 and concentrated with ethyl acetate was subjected to TLC analysis using three mobiles phase, namely chloroform: benzene: methanol: ethyl acetate $(4: 2: 2: 1)$, chloroform: methanol: ethyl acetate $(2: 1: 1)$, and chloroform: methanol: ethyl acetate $(2: 1: 1)$. After airdrying, the plates were visualized with iodine vapors. Among three mobile phases, the plate developed with solvent system 3 gave the best separation. A total of three different spots were obtained from $M$. marina KPMS1 sample with $R_{f}$ values of $0.76,0.62,0.51$, and 0.42 .

Table 1: Identification of Micromonospora isolates

\begin{tabular}{lllll}
\hline $\begin{array}{l}\text { Isolated } \\
\text { strains }\end{array}$ & Mycelium & Color of mycelium & Pigmentation & Carbohydrate utilization \\
\hline KPMS 1 & SM & Greenish gray & Yellowish green & Acid butt and alkaline slant \\
KPMS 9 & SM & Dull white & Diffusible yellowish brown & Acid butt, acid slant with gas production \\
KPMS 10 & AM/SM & Whitish ash & Diffusible red wine & Acid butt and alkaline slant \\
KPMS 13 & SM & Dark gray & Pale yellow & Acid butt and alkaline slant \\
KPMS 17 & SM & Brownish yellow & - & Acid butt and alkaline slant \\
KPMS 19 & SM & Whitish gray & - & Acid butt, acid slant with gas production \\
\hline
\end{tabular}

Table 2: Biochemical properties of Micromonospora isolates

\begin{tabular}{|c|c|c|c|c|c|c|c|c|}
\hline Isolated strain & Indole & MR & VP & Citrate & Catalase & Oxidase & Starch & Urease \\
\hline KPMS 1 & + & + & - & - & + & + & + & + \\
\hline KPMS 9 & + & + & - & - & - & - & - & + \\
\hline KPMS 10 & + & - & + & - & + & + & - & + \\
\hline KPMS 13 & + & + & - & - & - & + & + & + \\
\hline KPMS17 & + & - & + & - & - & - & - & + \\
\hline KPMS 19 & + & + & - & - & + & - & - & + \\
\hline
\end{tabular}


In secondary antibacterial screening of $M$. marina KPMS1, the fraction one showed highly sensitive to E. coli $18 \pm 0.07 \mathrm{~mm}$ with $87 \%$, P. aeruginosa $17 \pm 0.06 \mathrm{~mm}$ with $77 \%$, and E. faecalis $17 \pm 0.05 \mathrm{~mm}$ with $81 \%$ of the relative zone of inhibition. As compared to standard antibiotic cefotaxime, the percentage of the relative inhibitory zone was found to range between $77 \%$ and $87 \%$ [Table 4 ]. The results clearly demonstrate that a Gram-negative bacterium $E$. coli was highly susceptible to the tested crude extracts compared to Gram-positive E. faecalis bacteria. The $M$. marina KPMS1 showed significant antibacterial activity against multidrug-resistant Gram-negative and Gram-positive bacteria and it proved a promising antibacterial strains. The screening of the antimicrobial metabolites derived from Micromonospora isolates is often encountered and showed antibacterial activity against multidrug-resistant bacteria isolated from human beings [21]. The unusual antibiotic profile exhibited from Micromonospora strains was isolated from marine sediment and its biopotential activity against multidrug-resistant bacterial pathogens [13].

The active fraction showed a dose-dependent antimicrobial activity against the pathogen tested with zones of inhibition ranging from 17 and $19 \mathrm{~mm}$ in size at $2 \mathrm{mg} / \mathrm{ml}$. The minimal concentration to inhibit the tested bacterial pathogen was determined by microdilution method, indicating that the minimum inhibitory concentration of active fraction was $6.2-12.5 \mu \mathrm{g} / \mathrm{ml}$. This could be either due to the low concentration of the active inhibitory molecules or the presence of molecules with high inhibition constant. The MIC varied among the tested compounds against E. coli. These results were similar with the other report [22].

\section{Detection of bioactive compound}

In chemical screening, the crude potential fractions of $M$. marina KPMS1 recovered after fermentation were purified by TLC and identified with

Table 3: Preliminary screening of $M$. marina KPMS1 against multidrug-resistant bacteria with standard drug

\begin{tabular}{llll}
\hline Samples & E. coli & P. aeruginosa & E. faecalis \\
\hline Cefotaxime & $16 \mathrm{~mm}$ & $17 \mathrm{~mm}$ & $15 \mathrm{~mm}$ \\
KPMS 1 & $18 \pm 0.04 \mathrm{~mm}$ & $17 \pm 0.01 \mathrm{~mm}$ & $16 \pm 0.08 \mathrm{~mm}$ \\
Negative control & $4 \mathrm{~mm}$ & $4 \mathrm{~mm}$ & $4 \mathrm{~mm}$ \\
RIZD (\%) & 88 & 76 & 80 \\
\hline
\end{tabular}

M. marina: Micromonospora marina, E. coli: Escherichia coli, P. aeruginosa:

Pseudomonas aeruginosa, E. faecalis: Enterococcus faecalis
FT-IR and NMR analysis [23]. The FT-IR spectral analysis was carried out to determine the functional groups present in the M. marina KPMS1. The active fraction of spectra was scanned in the $4000-400 \mathrm{~cm}^{-1}$ and plotted as intensity and wave number. The absorption bands were exhibited at $3465.78 \mathrm{~cm}^{-1}-1095.33 \mathrm{~cm}^{-1}$ (Fig. 1). A broad stretching in the region $3465.78 \mathrm{~cm}-1$ (O-H stretching), $2929.32 \mathrm{~cm}-1$ (C-H stretching), $2361.93 \mathrm{~cm}-1$ (C-N stretching), $1635.42 \mathrm{~cm}-1$ (C = O stretching), and $1095.33 \mathrm{~cm}-1$ (C-O stretching) was observed. The NMR analysis of M. marina KPMS1 chemical structure was predicted as $2-(2 \mathrm{E}, 4 \mathrm{E})-3$, 7-dimethylocta-2,4-dienyl)-7-hydroxy-2,3,4,5-tetrahydrobenzo[c] azepin-1-one. The molecular weight of compound was 313.43388 and the molecular formula was $\mathrm{C}_{20} \mathrm{H}_{27} \mathrm{NO}_{2}$. The FT-IR and NMR analysis was more or less similar trend which was observed with other researcher [24]. The active compounds derived from marine sediments showed a good actinobacterial activity and can be used as an industrially important one [25].

\section{Phylogenetic relationship}

The monitoring of different Micromonospora strains in species levels was done by molecular techniques. The genomic DNA was extracted from M. marina KPMS1 and amplified for $16 \mathrm{~S}$ rRNA gene using the primers F243 and R513GC [26]. The size of amplified 16S rRNA gene product of $M$. marina KPMS1 was approximately $900 \mathrm{bp}$. The samples were sequenced and compared for homology with other bacterial strain sequences deposited in the public databases using the National Center for Biotechnology Information BLAST function. The GenBank accession number of M. marina KPMS1 was MH036351.

The phylogenetic evolutionary analysis was performed in MEGA 5.05 [27]. The sequence analysis usually includes alignment of sequences, construction of a phylogenetic tree, and testing the reliability of the constructed tree. The relationships of the aligned sequences are usually shown as a tree, in which the branching pattern of the tree displays the evolutionary relationships of the M. marina KPMS1. The most commonly applied tree construction method is distance method in which neighbour joining uses pair-wise distances calculated from aligned sequences before correcting to evolutionary distances in a substitution model [28]. The shortest distant sequences were clustered together in a tree and its length was optimized to the correspondent distance matrix.

The phylogenetic tree of M. marina KPMS1 was constructed using 16S rRNA gene sequence with that of other Micromonospora species.

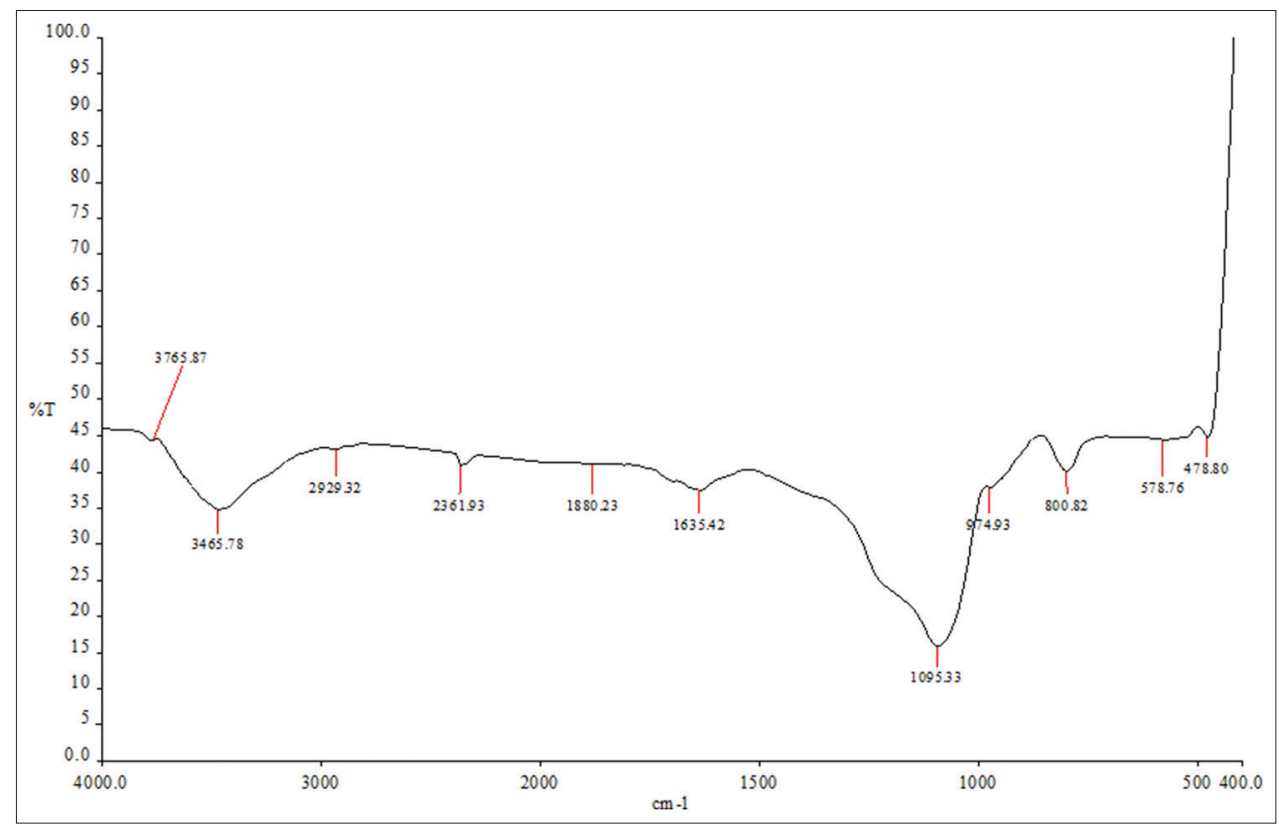

Fig. 1: Fourier-transform infrared spectral analysis of Micromonospora marina KPMS1 


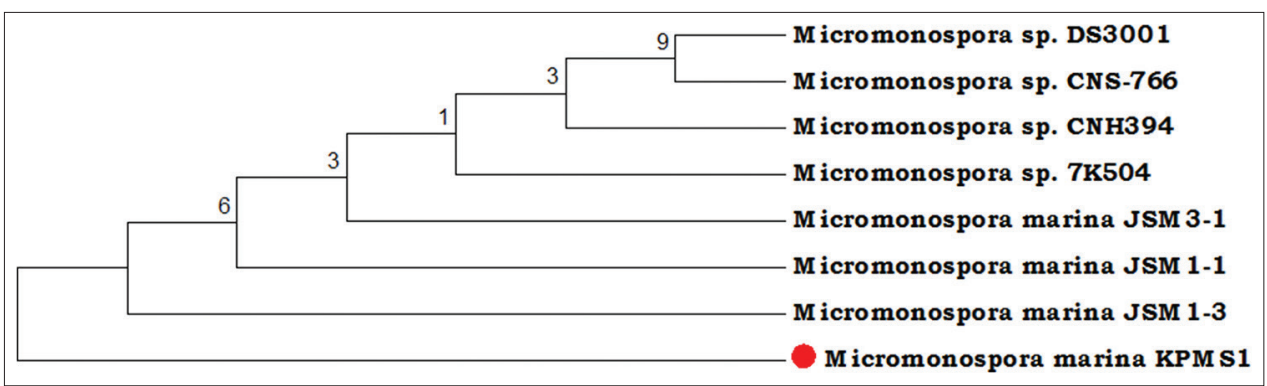

Fig. 2: Phylogenetic relationship of Micromonospora marina KPMS1

Table 4: Secondary screening of M. marina KPMS1 against multidrug-resistant bacteria

\begin{tabular}{llll}
\hline Samples & E. coli & P. aeruginosa & E. faecalis \\
\hline KPMS1 & $18 \pm 0.07 \mathrm{~mm}$ & $17 \pm 0.06 \mathrm{~mm}$ & $17 \pm 0.05 \mathrm{~mm}$ \\
RIZD (\%) & 87 & 77 & 81 \\
\hline
\end{tabular}

M. marina: Micromonospora marina, E. coli: Escherichia coli, P. aeruginosa:

E. faecalis: Enterococcus faecalis

The optimal tree with the sum of branch length 1.15000000 was analyzed [Fig. 2]. The tree was drawn to scale, with branch lengths in the same units as those of the evolutionary distances used to infer the phylogenetic tree. The evolutionary distances were computed using p-distance method and are in the units of the number of base substitutions per site. The phylogenetic tree showed two clades (I and II). The Clade I was subdivided into six smaller groups which encompass M. marina JSM1-3, M. marina JSM1-1, M. marina JSM3-1, Micromonospora sp. 7K504, Micromonospora sp. CNH394, and Micromonospora sp. DS3001. The Clade II encompassed the strain M. marina KPMS1. This analysis involves eight nucleotide sequences. The codon positions included were $1^{\text {st }}+2^{\text {nd }}+3^{\text {rd }}+$ noncoding. All positions containing gaps and missing data were eliminated. There were a total of 50 positions in the final dataset.

\section{CONCLUSION}

A genus Micromonospora are widely distributed in the marine environments and documented as a potential source of bioactive compounds. Among actinomycetes groups, Streptomyces sp. is considered as the dominant group found in the marine environment and also used for antibiotic research. Micromonospora is a rare group of actinomycetes which has been regarded as reservoir for antimicrobial agents. It had been emphasized that marine sediments might be valuable for the isolation of a novel strain of Micromonospora which potentially yield a broad spectrum of secondary metabolites. In reports suggested from the East Coast of India, soil is a major and suitable source of actinomycetes isolation. Correspondingly, the Kayalpatnam marine ecosystem is not only rich in biodiversity but also recognized a world heritage site and may provide the rich source for the discovery of Micromonospora sp. This study concludes that marine M. marina KPMS1 is well-organized novel secondary metabolites synthesizer and holds potential for the treatment of clinical associated infection, acute lymphocytic leukemia, and cancer in other types. The screening of antimicrobial metabolite is a significant role toward the greater demand for new metabolites for the benefit of mankind and synthesized a lot of promising genera derived from marine sediment of Micromonospora sp. having medicinal importance in future.

\section{AUTHORS' CONTRIBUTIONS}

Each author has contributed to the best of our knowledge for the research carried out in this article.

\section{CONFLICTS OF INTEREST}

The authors declared that they have no conflicts of interest.

\section{ACKNOWLEDGMENTS}

The authors thank the PG and Research Department of Microbiology, Jamal Mohamed College (Autonomous), Tiruchirappalli - 620 020, Tamil Nadu, India, toward this research work hereby acknowledged.

\section{REFERENCES}

1. Zhao H, Kassama Y, Young M, Kell DB, Goodacre R. Differentiation of Micromonospora isolates from a coastal sediment in wales on the basis of fourier transform infrared spectroscopy, 16S rRNA sequence analysis, and the amplified fragment length polymorphism technique. Appl Environ Microbiol 2004;70:6619-27.

2. Genilloud O. Genus micromonospora ørskov 1923, 156AL. In: Bergey’s Manual of Systematic Bacteriology. Vol. 5. New York: Springer; 2012. p. 1039-57.

3. Tanasupawat S, Jongrungruangchok S, Kudo T. Micromonospora marina sp. Nov. isolated from sea sand. Int J Syst Evol Microbiol 2010;60:648-52

4. Supong K, Suriyachadkun C, Pittayakhajonwut P, Suwanborirux K, Thawai C. Micromonospora spongicola sp. Nov. an actinomycete isolated from a marine sponge in the Gulf of Thailand. J Antibiot (Tokyo) 2013;66:505-9.

5. Fenical W, Jensen PR. Developing a new resource for drug discovery: Marine actinomycete bacteria. Nat Chem Biol 2006;2:666-73.

6. Chambers HF. General principles of antimicrobial therapy. In: Brunton LL, Lazo J, Parker K, editors. Goodman and Gilman's Pharmacological Basis of Therapeutics. $11^{\text {th }}$ ed. New York: McGraw-Hill; 2006. p. 1095-111.

7. Bérdy J. Bioactive microbial metabolites. J Antibiot (Tokyo) 2005;58:1-26

8. Blunt JW, Copp BR, Keyzers RA, Munro MH, Prinsep MR. Marine natural products. Nat Prod Rep 2012;29:144-222.

9. Pathom-aree W, Stach JE, Ward AC, Horikoshi K, Bull AT, Goodfellow M. Diversity of actinomycetes isolated from challenger deep sediment $(10.898 \mathrm{M})$ from the Mariana trench. Extremophiles 2006;10:181-9.

10. Abbas IH. A biological and biochemical studies of actinomycetes isolated from Kuwait saline soil-Kuwait. J Appl Sci Res 2006;2:809-15.

11. Savitri NA, Astana N, Azmi W. Microbial lasparagenase: A potent anti-tumor enzyme. Indian J Biotechnol 2003;2:184-94.

12. Laidi RF, Kansoh AL, Elshafei AM, Cheikh B. Taxonomy, identification and biological activities of novel isolate of Streptomyces tendae. Arab J Biotechnol 2006;9:427-36.

13. Sharma D, Kaur T, Chadha BS, Manhas RK. Antimicrobial activity of actinomycetes against multidrug resistant Staphylococcus aureus, E. coli and various other pathogens. Trop J Pharm Res 2011;10:801-8.

14. Subramani R, Aalbersberg W. Culturable rare actinomycetes: Diversity, isolation and marine natural product discovery. Appl Microbiol Biotechnol 2013;97:9291-321.

15. Tiwari K, Dilip JU, Eva M, Roderich S, Rajinder KG. Culturable bioactive actinomycetes from the great Indian Thar desert. Ann Microbiol 2015;65:1901-14

16. Bérdy J. Thoughts and facts about antibiotics: Where we are now and where we are heading. J Antibiot (Tokyo) 2012;65:385-95.

17. Sánchez López JM, Martínez Insua M, Pérez Baz J, Fernández Puentes JL, Cañedo Hernández LM. New cytotoxic indolic metabolites from a marine Streptomyces. J Nat Prod 2003;66:863-4.

18. Nagaseshu P, Gayatridevi V, Kumar BA, Kumari S, Mohan GM, Malla RR. Antioxidant and antiproliferative potentials of marine actinomycetes. Int J Pharm Pharm Sci 2016;8:277-84. 
19. Sallam LA, El-Refai AF, Osman ME, Hamdy AA, Ahmed EM, Mohamed MA. Some physiological factors affecting rapamycin production by Streptomyces hygroscopicus ATCC 29253. J Am Sci 2010;6:188-94.

20. Sarquis MI, Oliveira EM, Santos AS, Costa GL. Production of L-asparaginase by filamentous fungi. Mem Inst Oswaldo Cruz 2004;99:489-92.

21. Kokare CR, Mahadik KR, Kadam SS, Chopade BA. Isolation, characterization and antimicrobial activity of marine halophilic Actinopolyspora species AH1 from the West coast of India. Curr Sci 2004;86:593-7.

22. Sibanda T, Mabinya LV, Mazomba N, Akinpelu DA, Bernard K, Olaniran AO, et al. Antibiotic producing potentials of three freshwater actinomycetes isolated from the Eastern Cape province of South Africa. Int J Mol Sci 2010;11:2612-23.

23. Tiwari K, Gupta RK. Rare actinomycetes: A potential storehouse for novel antibiotics. Crit Rev Biotechnol 2012;32:108-32
24. Janardhan A, Kumar AP, Viswanath B, Saigopal DV, Narasimha G. Production of bioactive compounds by actinomycetes and their antioxidant properties. Biotechnol Res Int 2014;2014:217030.

25. Sheik GB, Maqbul MS, Shankar SG, Ranjith MS. Isolation and characterization of actinomycetes from soil of ad-dawadmi, Saudi Arabia and screening their antibacterial activities. Int J Pharm Pharm Sci 2017;9:276-9.

26. Ravikumar S, Fredimoses FM, Gokulakrishnan R. Biodiversity of actinomycetes in Manakkudi mangrove ecosystem, South West coast of Tamil Nadu, India. Ann Biol Res 2011;2:76-82.

27. Tamura K, Peterson D, Peterson N, Stecher G, Nei M, Kumar S, et al. MEGA5: Molecular evolutionary genetics analysis using maximum likelihood, evolutionary distance, and maximum parsimony methods. Mol Biol Evol 2011;28:2731-9.

28. Nei M, Kumar S. Molecular Evolution and Phylogenetics. New York: Oxford University Press; 2000 